\title{
EFFECTS OF ACHIEVING SUPPLY CHAIN FLEXIBILITY
}

\author{
Lenka Veselovská
}

Received: November 7, 2019 / Revised: January 9, 2020 / Accepted: February 12, 2020

(C) Association of Economists and Managers of the Balkans, 2020

\begin{abstract}
This research study focuses on the current topic of supply chain management which serves as a tool for manufacturing enterprises to cope with pressure put on them by continuously changing market conditions and the global economy itself. Paper presents the results of research conducted on the sample file of Slovak production enterprises. The main aim of this research study is to explore the extent of achieving agility, adaptability and alignment as secondary effects of supply chain flexibility in Slovak manufacturing enterprises. Representativeness of the sample file was confirmed by the application of Pearson's chi-squared test ( $\chi 2$ - test) due to the criterion of an enterprise's size. The results of this research provide a clear image of business reality in terms of supply chain organization and therefore have implications for business practice which may serve managers in their decision-making process in supply chain management.
\end{abstract}

Keywords: Flexibility, Supply Chain Management, Agility, Adaptability, Alignment.

\section{JEL Classification M11}

This paper was presented at the Third International Scientific Conference on IT, Tourism, Economics, Management and Agriculture - ITEMA 2019 - October 24, Bratislava, Slovakia, www.itema-conference.com

Lenka Veselovská

lenka.veselovska@umb.sk

1 Institute of Managerial Systems, Faculty of Economics, Matej Bel University, Francisciho 910/8, 058 01 Poprad, Slovak Republic 


\section{INTRODUCTION}

In the $21^{\text {st }}$ century manufacturing enterprises face severe competition which puts that much pressure not only on their production process requirements but also on their supply chain activities. It is the main aim of every enterprise's management to ensure the best possible outcome and gain the competitive advantage which enables an enterprise to establish a desirable market position. However, nowadays it is not just a simple competition among various individual enterprises, but their supply chains as whole systems.

The premise of this study is that both partner collaboration and flexibility are multidimensional concepts; managers must understand how various supply chain activities correspond to different dimensions of flexibility and what the possible outcomes are. An extensive review of the secondary effects of supply chain flexibility increase is a natural extension of existing studies on the topic of supply chain flexibility and development. Given these problems, we undertook an empirical study among manufacturing enterprises in Slovakia to determine the effects of achieving supply chain flexibility in practice through the lens of supply chain agility, adaptability and alignment. Research results on the topic are presented in an attempt to gain a better understanding of current business reality and provide an insight into outcomes of supply chain flexibility in terms of secondary effects.

\section{LITERATURE REVIEW}

The ability to respond to external and internal stimuli decides an enterprise's development and economic outcomes. Such flexibility is now one of the strategic goals of significant amount of enterprises. On an even higher level is the supply chain flexibility which can be considered as "the ability of a supply chain to respond to market changes in order to gain or maintain competitive advantage" (Moon et al., 2012). Gong (2008) found that flexibility, cost, quality, and technology are considered as the strategic core areas of the enterprise and therefore are a significant focus of research (Gaimon \& Singhal, 1992; Chuu, 2011; Púchovská et al., 2017; Bartková, 2017; Mackelprang et al., 2014).

Effective supply chain management is an essential part of an enterprise's integrated management especially in the manufacturing industry. It focuses on aiding enterprises to avoid losses resulting from information asymmetry, unnecessary increases in inventory turnover and logistics costs. The most important sources of successful and well-organized supply chain management originate from measures designed to improve supply chain flexibility. However, such methods also provide many side-effects that can be both beneficial and threatening for enterprises. No tool should be applied without knowing precisely what outcomes to expect and how to avoid unnecessary risks. On the other hand, positive outcomes can help an enterprise to further increase its performance. Several authors focused on evaluating the negative outcomes of supply chain flexibility (Yee, 2007; Sodhi \& Tang, 2012; Sodhi \& Lee, 2007; Cantor et al., 2014). However, there is a lack of scientifically verified information on positive outcomes of supply chain flexibility in terms of its secondary effects.

Furthermore, a great deal of attention has also been assigned to the creation of measures designed to achieve the flexibility of supply chain (Das, 2011; Chopra \& Sodhi 2004, Stevenson \& Spring, 2007; Závadský \& Závadská, 2014; Akyuz \& Erkan, 2010). Aside from an increase in flexibility, such measures can also aid in strengthening the enterprise's position in the supply chain and provide support for the entire supply chain to gain other abilities that make it more competitive. Agility is 
one of these possible outcomes. It provides the ability of a supply chain to respond rapidly to quick changes in both demand and supply on the market. Furthermore, agility also strengthens the ability of the whole supply chain to successfully deal with unanticipated external disruptions efficiently and to rapidly recover from shocks with the minimal cost increase. The biggest challenge in terms of agility is to apply such flexibility measures that enable an enterprise to gain the ability to respond to short term changes in demand and supply quickly. Another effect of making the supply chain more flexible can lead to its ability to evolve over time as economic progress, political shifts, demographic trends and technological advances reshape markets. This is frequently referred to as supply chain adaptability. It can also be achieved by adjusting the supply chain design to accommodate market changes, however, this process of redesigning the supply chain can be challenging. The highest level of cooperation in the supply chain can lead to its alignment. This term stands for the ability of a supply chain to coordinate and align the interests of all participating enterprises. As a result, as each enterprise maximizes its own interests, it optimizes the chain's performance as well. The main challenge in terms of alignment is to establish incentives for supply chain partners to improve performance of the entire chain (Lee, 2004; El Mokadem, 2016; Blakyta et al. 2017; Bartková, 2019).

\section{AIMS AND METHODS}

The main aim of this research study is to explore the extent of achieving agility, adaptability and alignment as secondary effects of supply chain flexibility in Slovak manufacturing enterprises. In order to fulfill this objective empirical research used data provided by selected enterprises via survey which was conducted in a period between May 2018 and August 2018.

The research sample file was created as a representative sample of the base file (Table 1). The criterion of the size of company was taken into account. The focus of this research was on all enterprises in this sector of economy, since the assumption was that they had a higher extent of flexibility measures applications. The decisive criterion was set according to the European Standard No. 2003/361/EC. To verify the representativeness of the sample Chi-square test was used. The test was performed at a significance level of $95 \%$. The verification proved that this sample file is representative. A number of statistical methods were used to analyze the data. Pearson correlation test and factor analysis were used to examine relationships among selected variables. In order to describe significant relationships in detail correlation coefficients were used. Particular correlation coefficients were also calculated.

Table 1. Structure of base file based on the size of company

\begin{tabular}{|c|c|c|}
\hline Number of employees & Number of companies & Percentage \\
\hline $0-9$ & 201 & $62.42 \%$ \\
\hline $10-49$ & 78 & $24.22 \%$ \\
\hline $50-249$ & 31 & $9.63 \%$ \\
\hline over 250 & 12 & $3.73 \%$ \\
\hline Total & $\mathbf{3 2 2}$ & $\mathbf{1 0 0 . 0 0 \%}$ \\
\hline
\end{tabular}

\section{RESULTS AND DISCUSSION}

Firstly, the relationships between flexibility types and various factors were explored. The correlation coefficient was used to evaluate these relations and to discover significant dependences between factors (Table 2). We examine these flexibilities types: contract flexibility (CFL), volume flexibility (VFL), product mix flexibility (PFL), delivery flexibility (DFL) and manufacturing flexibility (MFL). 
Table 2. Dependences between flexibility types and various factors

\begin{tabular}{|c|c|c|c|c|c|}
\hline $\begin{array}{c}\text { Flexibility } \\
\text { types }\end{array}$ & $\begin{array}{c}\text { No. } \\
\text { of suppliers }\end{array}$ & $\begin{array}{c}\text { No. } \\
\text { of customers }\end{array}$ & $\begin{array}{c}\text { Size } \\
\text { of enterprise }\end{array}$ & $\begin{array}{c}\text { Supply chain } \\
\text { structure }\end{array}$ & $\begin{array}{c}\text { Position in } \\
\text { supply chain }\end{array}$ \\
\hline CFL & 0.091 & 0.137 & 0.128 & 0.107 & 0.137 \\
\hline VFL & 0.741 & 0.386 & 0.422 & -0.151 & 0.186 \\
\hline PFL & -0.316 & -0.091 & -0.440 & 0.018 & -0.091 \\
\hline DFL & 0.728 & 0.753 & 0.177 & -0.196 & 0.153 \\
\hline MFL & 0.603 & 0.568 & 0.855 & 0.364 & 0.268 \\
\hline
\end{tabular}

These results indicate there is no significant dependence between any of the examined flexibility types and the enterprise's position in the supply chain. However, the size of the enterprise proofs to be different. There is a medium-strong direct dependence between size and volume flexibility. This result indicates that larger Slovak enterprises are more likely to achieve a significant level of volume flexibility throughout their supply chain. Furthermore, according to the data provided, there is a significant indirect dependence between product mix flexibility and both the enterprise's size and the number of suppliers. This means that smaller enterprises with fewer suppliers are more likely to achieve the ability to make rapid changes in their products than larger enterprises. This is an interesting finding. However, the nature of the product has to be taken into consideration. Smaller enterprises usually manufacture products with fewer components and fewer activities in their manufacturing process, which makes it less difficult to make rapid changes. On the other hand, manufacturing flexibility is easier to achieve by larger enterprises that operate with more recourses available for redeployment when necessary. An interesting finding is a fact that delivery flexibility is not dependable neither with the size of enterprise not its position in supply chain and contract flexibility has essentially no relationship with any of the examined factors.

Secondary effects in terms of agility, adaptability and alignment were also examined. Firstly, we take a closer look at the levels of these three supply chain characteristics in relation to levels of supply chain flexibility. Table 3 provides data about the percentage of enterprises with certain levels of supply chain agility structured by levels of supply chain flexibility. Data indicates that $13.66 \%$ of all manufacturing enterprises consider their level of supply chain agility as high. Furthermore, only $8.70 \%$ of all enterprises in the sample file consider both their level of supply chain flexibility and level of supply chain agility as high. On the other hand, only even fewer enterprises $(5.90 \%)$ perceive both their level of supply chain flexibility and supply chain agility as low. Almost one-third of all enterprises $(29.19 \%)$ consider their supply chain agility to be low.

Table 3. Levels of supply chain agility

\begin{tabular}{|c|c|c|c|}
\hline \multirow{2}{*}{ Level of SC agility } & \multicolumn{3}{|c|}{ Level of SC flexibility } \\
\cline { 2 - 4 } & high & medium & low \\
\hline high & $8.70 \%$ & $4.66 \%$ & $0.31 \%$ \\
\hline medium & $26.09 \%$ & $24.53 \%$ & $6.52 \%$ \\
\hline low & $5.90 \%$ & $17.39 \%$ & $5.90 \%$ \\
\hline
\end{tabular}

Table 4 provides information about levels of supply chain adaptability in relation with levels of supply chain flexibility. According to the data, overall levels of supply chain adaptability are considerably lower that levels of supply chain agility. This finding is especially obvious in group of enterprises with high level of supply chain flexibility. Overall less than $10 \%$ of all manufacturing enterprises consider their level of supply chain adaptability high. On the other hand, $42.55 \%$ of 
enterprises have low level of supply chain adaptability. Furthermore, levels of supply chain alignment were examined. According to the data provided in Table 5, it is obvious that this secondary effect of supply chain flexibility is achieved by very few enterprises. Only $18.01 \%$ of Slovak manufacturing enterprises have medium or high levels of supply chain alignment. Moreover, less than $1 \%$ of enterprises with high levels of supply chain flexibility are able to also achieve high levels of supply chain alignment. Even more concerning is the finding that $35.71 \%$ of Slovak manufacturing enterprises have high supply chain flexibility, but only low levels of supply chain alignment.

Table 4. Levels of supply chain adaptability

\begin{tabular}{|c|c|c|c|}
\hline \multirow{2}{*}{$\begin{array}{c}\text { Level of SC } \\
\text { adaptability }\end{array}$} & \multicolumn{3}{|c|}{ Level of SC flexibility } \\
\cline { 2 - 4 } & high & medium & low \\
\hline high & $4.35 \%$ & $4.97 \%$ & $0.31 \%$ \\
\hline medium & $17.70 \%$ & $25.47 \%$ & $4.66 \%$ \\
\hline low & $18.63 \%$ & $16.15 \%$ & $7.76 \%$ \\
\hline
\end{tabular}

Table 5. Levels of supply chain alignment

\begin{tabular}{|c|c|c|c|}
\hline \multirow{2}{*}{ Level of SC alignment } & \multicolumn{3}{|c|}{ Level of SC flexibility } \\
\cline { 2 - 4 } & high & medium & low \\
\hline high & $0.62 \%$ & $2.17 \%$ & $0.00 \%$ \\
\hline medium & $4.35 \%$ & $6.52 \%$ & $4.35 \%$ \\
\hline low & $35.71 \%$ & $37.89 \%$ & $8.39 \%$ \\
\hline
\end{tabular}

Since it was discovered that different flexibility types can have different effects on overall supply chain performance, a more detailed examination of relationship between flexibility types and levels of agility, adaptability and alignment was conducted. Table 6 provides data about such relationships expresses by calculated correlation coefficients. It is important to explore which flexibility type or types have significant effect on achievement of secondary effects such as supply chain agility, adaptability and alignment. According to the data the majority of significant relationships with secondary effects can be found in correlations with delivery flexibility. Volume and manufacturing flexibility also have some significant dependences with levels of supply chain agility, adaptability and alignment. It was discovered that the weakest relationship is between product flexibility and level of both supply chain adaptability and alignment.

Table 6. Dependences between flexibility types and levels of supply chain agility, adaptability and alignment

\begin{tabular}{|c|c|c|c|}
\hline \multirow{2}{*}{ Flexibility types } & \multicolumn{3}{|c|}{ Level of SC } \\
\cline { 2 - 4 } & agility & adaptability & alignment \\
\hline CFL & 0.473 & 0.469 & 0.365 \\
\hline VFL & 0.801 & 0.681 & 0.572 \\
\hline PFL & 0.497 & 0.318 & 0.295 \\
\hline DFL & 0.839 & 0.791 & 0.652 \\
\hline MFL & 0.740 & 0.637 & 0.611 \\
\hline
\end{tabular}

\section{CONCLUSION}

The main aim of this research study is to explore the extent of achieving agility, adaptability and alignment as secondary effects of supply chain flexibility in Slovak manufacturing enterprises. Achieved results provide a current image of Slovak business reality in its production industry through the lens 
of supply chain flexibility as one of the current trends. There had not been similar studies covering the Slovak reality in the last decade. Previous results do not consider a wide use of computers as support systems for flexibility achievement and therefore any comparison with our achieved results would not provide significant conclusions. Moreover, the attitude towards supply chain management has evolved significantly. Consequently, our findings can only be compared to similar studies conducted in other business sectors or economies and therefore, detailed comparisons cannot be provided.

Garo and Guimarães (2018) focused their research on competitive priorities and strategic alignment as mediators in the relationship between companies in the Brazilian automotive supply chain. They discovered that there is a strategic alignment in the chain, mainly driven by the automaker and the systems suppliers and that competitive priorities shape the forms of the relationships between companies in the automotive supply chain. Similar results were achieved in this study in terms of the relationship between the level of supply chain alignment and the enterprise's position in the supply chain. Dubey et al. (2018) examined supply chain agility, adaptability and alignment in the Indian auto components industry. This research study provides the best possible option for comparison since both the object and the subject of research are similar to this study. It was discovered that when and how organizations create agility, adaptability, and alignment differs depending on distinct supply chain properties. Their statistical analyses suggest that information sharing and supply chain connectivity resources influence supply chain visibility capability, which enhances supply chain agility, adaptability, and alignment. Our findings are similar in terms of the effects of various factors such as position in the supply chain, the structure of supply chain and enterprise's size. The finding of a significant relationship between the level of alignment with supply chain structure is consistent with its direct relationships with delivery flexibility and with manufacturing flexibility. Findings from other studies provide further evidence to support these findings (Kabra \& Ramesh, 2016; Tan et al., 2010; Agarwal et al., 2006).

Limitations of this research and consequently also achieved results lie in the lack of focus on measures applied to increase flexibility and their relationship with examined secondary effects. Therefore, this limitation provides several ideas for further research on this topic. One of the possible extensions of this study lies in creating a holistic study of the antecedents of agility, adaptability, and alignment under the scrutiny of applied flexibility measures. This study provides significant implications for both practice and researchers that could lead to the increased competitive advantage of enterprises and their supply chain. Achieved results can serve as a premise for further exploration of the examined topic by researchers and enrichment of information concerning the topic of supply chain flexibility.

\section{ACKNOWLEDGMENT}

This contribution was supported by the project No. 1/0757/18, "Consumer behaviour in buying goods of daily consumption with an emphasis placed different contents of goods offered on markets of selected EU countries".

\section{REFERENCES}

Agarwal A et al. (2006). Modeling the metrics of lean, agile and leagile supply chain: An ANPbased approach. European Journal of Operational Research, 173(1), 211-225. https://doi. org/10.1016/j.ejor.2004.12.005

Akyuz G.A., \& Erkan, T.E. (2010). Supply chain performance measurement: a literature review. International Journal of Production Research, 48(17), 5137-5155. https://doi. org/10.1080/00207540903089536 
Bartková L. (2017). Different contents of daily consumption goods offered on markets of selected EU countries. Proceedings from: Globalization and Its Socio-Economic Consequences. Conference Proceedings. Žilina : University of Žilina.

Bartková L. (2019). How do consumers perceive the dual quality of goods and its economic aspects in the European Union? An empirical study. Problems and Perspectives in Management, 17(3), 382-394. http://dx.doi.org/10.21511/ppm.17(3).2019.31

Blakyta, G. et al. (2017). Integral assessment of business environment security. Problems and Perspectives in Management, 15(4), 280-292. https://doi.org/10.21511/ppm.15(4-1).2017.12

Cantor, D.E. et al. (2014). The clock is ticking: The role of uncertainty, regulatory focus, and level of risk on supply chain disruption decision making behavior. Transportation Research Part E: Logistics and Transportation Review, 72, 159-172. https://doi.org/10.1016/j.tre.2014.10.007

Chopra S., \& Sodhi, M.S. (2004). Managing Risk to Avoid Supply Chain Breakdown. MIT Sloan Management Review, 46(1), 53-61.

Chuu, S.J. (2011). Interactive group decision-making using a fuzzy linguistic approach for evaluating the flexibility in a supply chain. European Journal of Operational Research, 213(1), 279-289. https://doi.org/10.1016/j.ejor.2011.03.022

Das, K. (2011). Integrating effective flexibility measures into a strategic supply chain planning model. European Journal of Operational Research, 211(1), 170-183. https://doi.org/10.1016/j. ejor.2010.12.006

Dubey, R. et al. (2018). Supply chain agility, adaptability and alignment: Empirical evidence from the Indian auto components industry. International Journal of Operations and Production Management, 38(1), 129-148. https://doi.org/10.1108/IJOPM-04-2016-0173

El Mokadem, M. (2016). ISO 9000 moderation role over supply chain alignment in manufacturing context. Journal of Manufacturing Technology Management, 27(3), 338-363. https://doi. org/10.1108/JMTM-03-2015-0015

Gaimon, C., \& Singhal, V. (1992). Flexibility and the choice of manufacturing facilities under short product life cycles. European Journal of Operational Research, 60(2), 211-223. https://doi. org/10.1016/0377-2217(92)90094-P

Garo, W.R., \& Guimarães, M.R.N. (2018). Competitive priorities and strategic alignment as mediators in the relationship between companies in the Brazilian automotive supply chain. South African Journal of Industrial Engineering, 29(1), 184-194. https://doi.org/10.7166/29-1-1791

Gong, Z. (2008). An economic evaluation model of supply chain flexibility. European Journal of Operational Research, 184(1), 745-758. https://doi.org/10.1016/j.ejor.2006.11.013

Kabra, G., \& Ramesh, A. (2016). Information Technology, Mutual Trust, Flexibility, Agility, Adaptability: Understanding Their Linkages and Impact on Humanitarian Supply Chain Management Performance. Risk hazards \& crisis in public policy, 7(2), 79-103. https://doi. org/10.1002/rhc3.12096

Lee, H.L. (2004). Triple A-supply chain. Harvard business review, 8096(1), 2-12. Mackelprang, A.W. et al. (2014). The Relationship Between Strategic Supply Chain Integration and Performance: A Meta-Analytic Evaluation and Implications for Supply Chain Management Research. Journal of Business Logistics, 35(1), 71-96. https://doi.org/10.1111/jbl.12023

Moon, K.K.L. et al. (2012). An instrument for measuring supply chain flexibility for the textile and clothing companies. European Journal of Operational Research, 222(1), 191-203. https:// doi.org/10.1016/j.ejor.2012.04.027

Púchovská, J.L. et al. (2017). What are the critical success factors of business process standardization?. Proceedings from: Management and Economics Manufacturing. Global Scientific Conference on Management And Economics in Manufacturing. Zvolen: Technická Univerzita Zvolen. 
Sodhi, M.S., \& Lee, S. (2007). An analysis of sources of risk in the consumer electronics industry. Journal of Operational Research Society, 58, 1430-1439. https://doi.org/10.1057/palgrave. jors. 2602410

Sodhi, M.S., \& Tang, C.S. (2012). Strategic approaches for mitigating supply chain risks. International Series in Operations Research \& Management Science, 172(1), 95-108. https://doi. org/10.1007/978-1-4614-3238-8_7

Stevenson, M., \& Spring, M. (2007). Flexibility from a supply chain perspective: definition and review. International Journal of Operations \& Production Management, 27(7), 685-713. https://doi.org/10.1108/01443570710756956

Yee, S. T. (2007). Impact analysis of customized demand information sharing on supply chain performance. International Journal of Production Research, 43(16), 3353-3373. https://doi. org/10.1080/00207540500095779

Závadský, J., \& Závadská, Z. (2014). Utilisation of business process models in managerial practice: An empirical study in Slovak companies certified to the ISO 9001 standard. Total Quality Management \& Business Excellence, 24(3-4), 319-337. https://doi.org/10.1080/14783363.201 3.791103 